\title{
ON THE SEARCH FOR NEODYMIUM-142 IN TERRESTRIAL ROCKS
}

\section{E. Jagoutz and R. Jotter}

Max-Planck-Institut fuer Chemie, Postfach 3060,D-55020,Mainz, Germany (jagoutz@mpch-mainz.mpg.de).

\section{Abstract:}

Neodymium- $-{ }^{142} \mathrm{Nd}$ is a decay product of ${ }^{146} \mathrm{Sm}$ (half-life of $103 \mathrm{Myr}$ ). ${ }^{146} \mathrm{Sm}$ is a so-called extinct radioisotope[1]. It existed 4.56 Ga ago $\left({ }^{146} \mathrm{Sm} /{ }^{144} \mathrm{Sm}\right.$ : $0.008 \pm 0.0011$ [2]) but was essentially extinct after $300 \mathrm{Myr}$. There is indirect evidence for the existence of ${ }^{146} \mathrm{Sm}$ by observation of ${ }^{142} \mathrm{Nd}$ variations in meteorites [1]. The first finding of ${ }^{142} \mathrm{Nd}$ in terrestrial rocks was reported from a single sample from the Isua supercrustals [3]. Several groups challenged this finding [4]. First attempts to find a ${ }^{142} \mathrm{Nd}$ anomaly on Earth was simply guided by measuring old rocks hoping that some of the Isua rocks are derived from an early differentiated reservoir. We found reasons to believe that some of the cratonic lithosphere might actually be a remnant of a primary differentiation. The first indication in this direction was the finding that the cratonic ultramafic in South Africa are having a higher modal abundance of orthopyroxene [5] than the primitive mantle. Later, the higher modal orthopyroxene contained was also demonstrated for the Siberian craton [6]. Herzberg actually proposed that this might be caused by primary differentiation on Earth [7]. We found that besides other geochemical peculiarities, a depletion of $\mathrm{Al}$ is
\end{abstract}

evident in such cratonic ultramafics. A geochemical parallelism is found in SNC meteorites and urelites. In SNC meteorites, variation in ${ }^{142} \mathrm{Nd}$ is evident [8] indicating that the $\mathrm{Al}$ deficit was caused by a very early differentiation. A similar style of primary differentiation could have produced the cratonic lithosphere. This made us search for a ${ }^{142} \mathrm{Nd}$ anomaly in cratonic ultramafics. In one of our samples we have found a $+30 \pm 10 \mathrm{ppm}$ deviation from the standard ${ }^{142 \mathrm{Nd} / 144} \mathrm{Nd}$ ratio. However, this needs further confirmation by additional measurements

\section{Introduction:}

The formation of the solar system was very fast. The oldest solid fragments condensed at $4.571 \mathrm{Ga}$, while at 4.557Ga (only 14 my later) basaltic magmas were generated on planetesimals, which in a short time formed the planets in the solar system. At $4.571 \mathrm{Ga}$ a number of radioactive isotopes existed which are extinct by now. In cosmochemisry we are using the decay products of such extinct isotopes in order to date the early evolution of the solar system: ${ }^{26} \mathrm{Al}-$ ${ }^{26} \mathrm{Mg},{ }^{53} \mathrm{Mn}-{ }^{53} \mathrm{Cr},{ }^{182} \mathrm{Hf}-{ }^{182} \mathrm{~W},{ }^{146} \mathrm{Sm}$ $-{ }^{142} \mathrm{Nd},{ }^{129} \mathrm{I}-{ }^{129} \mathrm{Xe}$ are some of the frequently used isotopic systems. From studies of the ${ }^{182} \mathrm{Hf}-{ }^{182} \mathrm{~W}$ system there 
is the clear conclusion that at $4.541 \mathrm{Ga}$ the formation of the Earth was completed. At this time a number of short-lived radioactive isotopes still existed. ${ }^{146} \mathrm{Sm}$ was present at this time $\left({ }^{146} \mathrm{Sm} /{ }^{144} \mathrm{Sm}\right.$ - 0,006). In a reservoir with a chondritic $\mathrm{Sm} / \mathrm{Nd}$ ratio the 142 $\mathrm{Nd}$ will have today the normal ${ }^{142} \mathrm{Nd} /{ }^{144} \mathrm{Nd}$ ratio, of 1.141733; while at $4.550 \mathrm{Ga}$ in the early Earth this ratio was 1.141233 . If we find a reservoir which was depleted earlier in Sm we expect to measure a lower than chondritic ${ }^{142} \mathrm{Nd} /{ }^{144} \mathrm{Nd}$. This effect is limited and as lower limit might be by a total depletion of $\mathrm{Sm}\left({ }^{142} \mathrm{Nd} /{ }^{144} \mathrm{Nd}=\right.$ 1.141233). On the other hand, in a reservoir where the $\mathrm{Sm} / \mathrm{Nd}$ ratio is higher than chondritic (light rare earth depleted reservoir) the ${ }^{142} \mathrm{Nd} /{ }^{144} \mathrm{Nd}$ will be higher than chondritic. The enrichment of ${ }^{142} \mathrm{Nd}$ is only limited by the degree of early REE depletion $(\mathrm{Sm} / \mathrm{Nd}$ ratio). However, this enrichment of ${ }^{142} \mathrm{Nd}$ will only occur so as long as ${ }^{146} \mathrm{Sm}$ was still present (300myr after formation of the Earth.) However, the enriched ${ }^{142} \mathrm{Nd}$ signature of the early-depleted reservoir will remain practically forever no matter what differentiation processes overprint the reservoir. The only way to destroy this enriched ${ }^{142} \mathrm{Nd}$ is to remix the early-enriched reservoir with the earlydepleted reservoir. That means that lithologies involved in the early differentiation of the Earth should possess a "marked" $\mathrm{Nd}$ isotopic composition even today.

\section{Experimental:}

We developed a method to measure high-precision ${ }^{142} \mathrm{Nd} /{ }^{144} \mathrm{Nd}$ ratios in order to measure SNC meteorites which are believed to represent rock fragments from planet Mars. Those meteorites are very expensive and some of these meteorites are only $20 \mathrm{~g}$ as a total sample. Therefore we had to develop a new method using only small samples. For this reason we measure $\mathrm{Nd}$ as $\mathrm{NdO}^{+}$ions in the mass spectrometer. While the measurement of $\mathrm{NdO}^{+}$is more sensitive, it has an additional correction (oxygen fractionation), which limits the precision of the results.

To eliminate all isobaric interferences (especially ${ }^{142} \mathrm{Ce}$ ) we established a special chemical extraction routine to isolate $\mathrm{Nd}$. However the challenge was to find a mass pectromeric routine to get the reproducibility to $7 \mathrm{ppm}$ and the precision to 10ppm. The "second order mass fractionation" was careful analysed and we where able to eliminate the causes of this source of error.

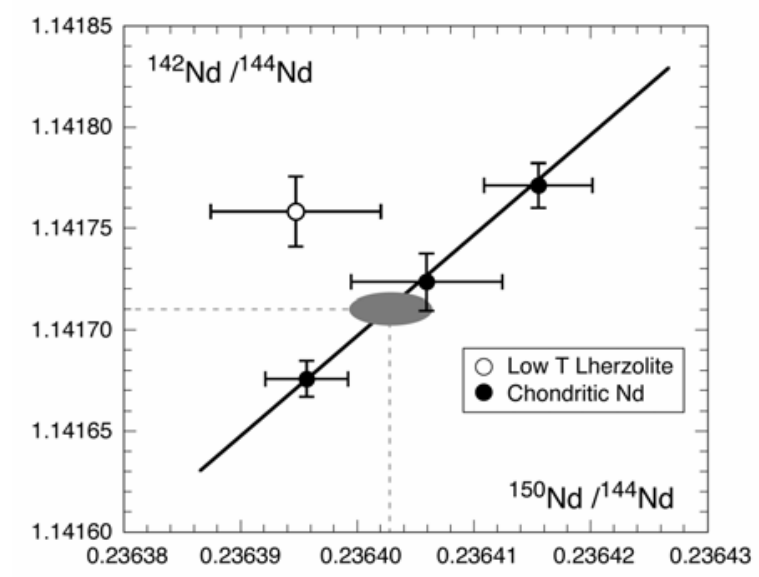




\section{Results:}

We measured a number of SNC meteorites and got a very good agreement in those cases where ${ }^{142} \mathrm{Nd}$ where already measured by other groups. These results will be published elsewhere. However, we also made an attempt to measure ${ }^{142} \mathrm{Nd}$ on terrestrial samples. The measurement of ${ }^{142} \mathrm{Nd}$ is very time consuming, taking about 3 weeks of work for one sample.

So far we have found two ultramafic xenoliths (low temperature lherzolites) out of five which have a ${ }^{142} \mathrm{Nd}$ anomaly. The final deviation from the chondritic ${ }^{142} \mathrm{Nd}$ is shown in the diagram. The fractionation of oxygen in the masspec is a serious problem in our setup as mentioned above. In order to quantify the influence of oxygen fractionation we plot ${ }^{142} \mathrm{Nd}$ versus ${ }^{150} \mathrm{Nd}$ both normalized to ${ }^{144} \mathrm{Nd}$ and to ${ }^{146} \mathrm{Nd} /{ }^{144} \mathrm{Nd}$ $=0.7219 .{ }^{150} \mathrm{Nd}$ is only affected by oxygen fractionation and for chondritic ${ }^{142} \mathrm{Nd}$ we find a correlation between ${ }^{142} \mathrm{Nd}$ and ${ }^{150} \mathrm{Nd}$. Most of the standard runs are plotting within the grey oval on this correlation line, while some of the extreme fractionated standard runs are plotted along the oxygen fractionation line. The two low temperature lherzolites, however, plot of this fractionation line because of elevated ${ }^{142} \mathrm{Nd}$.

\section{Discussion and conclusions:}

This results indicate that the cratonic lithosphere contain remnants of the primary differentiation of the earth. We selected this type of sample since to our opinion there were already signs of a very early differentiation in the chemical composition of the cratonic lithosphere. The first indication in this direction was the finding that the cratonic ultramafics in South Africa have a higher modal abundance of orthopyroxene [5] than the primitive mantle. Later, higher modal orthopyroxene was also showenfor the Siberian craton [6]. Herzberg actually proposed that this might be caused by a primary differentiation on Earth [7]. We found that, besides other geochemical peculiarities, a depletion of $\mathrm{Al}$ is evident in such cratonic ultramafics. A geochemical parallelism can be found in SNC meteorites.

References: [1] Lugmair and Marti (1977) EPSL,

35, 273-284. [2] Lugmair and Galer (1992) GCA 56,1673-1694. [3] Harper and Jacobsen (1992) Nature 360, 728732. [4]Goldstein S L and Galer SJG (1992)Eos P323; Sharma et al. (1996) GCA 60,2037-2047. [5] Boyd F. R. (1989) EPSL 96, 15-26.[6] Boyd F. R. et al. (1997) Cont. Min. Pet., 128,228246. [7] Herzberg C.T. (1993) EPSL 120,13-29. [8] Harper et al. (1995) Science 267, 213-217. 